THURSDAY, SEPTEMBER 29, I87o

\section{HOUSE ACCOMMODATION FOR LEARNED SOCIETIES}

THE movement which originated with the Statistical Society about three months ago for bringing under the shelter of one roof various learned societies of the metropolis, has already made that progress which gives the best assurance of ultimate success.

The "Learned Societies' Accommodation Committee" is at present constituted by delegates from the undermentioned bodies:- The Anthropological Society; the British Archæological Association; the East India Association ; the Ethnological Society ; the Institute of Actuaries; the Iron and Steel Institutes; the Juridical Society; the Meteorological Society ; the Photographic Society; the Royal Colonial Institute; the Society of Arts; the Social Science Association and Law Amendment Society ; the Statistical Society; and the Victoria Institute.

Each of these Societies is represented on the Committee by one delegate. The President of the Statistical Society, Mr. Newmarch, has been chosen chairman, but as this Society had already a delegate, the Chairman has no vote, otherwise the Society would have two voices at the Board, while the others, were restricted to one each.

The Committee reserve to themselves the "power to add representatives from other learned Societies." By this resolution the combining societies may be increased, and probably will be, as the scheme approaches nearer accomplishment.

One body named in the list above has so large a fellowship, and so wide a scope in its objects, that its wants are consequently great and peculiar. The Society of Arts is likely to need house room in, we believe, a year or two. This society, Mr. Le Neve Foster remarks, would require "all the room we have at present and something more." When their extensive premises in the Adelphi are brought to mind, it is at once felt that Mr. Foster's society stands apart by the magnitude of its essential wants from all the others just named. To a certain degree the needs of the Society of Arts do not accord with the humbler demands of the other societies. The latter may be housed in a moderately capacious building, with a common meeting room or theatre, capable of accommodating from 150 to 200 members. Hence, these smaller scientific bodies offer a much easier undertaking to organise and manage. In London the difficulties of obtaining an appropriate site are enormously multiplied by any large increase of required frontage. On the other hand, the union of the Society of Arts with the other learned bodies presents the opportunity of a bolder enterprise. A comprehensive project for lodging all the London societies lacking house-room in one mansion is, doubtless, an attractive idea to many minds. Thus, it would appear at first sight, that, under these circumstances, two courses emerge : a moderate plan, with proximate execution, for the smaller societies; a grander scheme, with, in all probability, indefinitely remote accomplishment.

The Committee have avoided, by the unanimous resolutions of the ist July, any conflict between these views. They have resolved in effect:

vol. II:
I. That convenient and permanent accommodation should be provided in a distinct building for societies that do not require extensive museums and libraries.

2. That the Committee express their earnest desire to co-operate with societies requiring larger accommodation for libraries and museums, either by "a combined application to Government for a site or building, or by joint action for the purchase of a convenient site."

The Committee think that if the wider co-operation spoken of in the second resolution should be successful, the plan for the smaller societies "may be either treated as a separate block in an associated group of buildings, or as a constituent part of one large building."

The Committee have taken the necessary step of giving instructions for the preparation by a competent architect of sketch plans and the elevation of a building adapted to the requirements of the smaller societies. These plans, it is understood, will be laid before the Committee when it re-assembles in October. Further, the Committee determined that the first subject for consideration at their next meeting " be the appointment of one or more of its members to represent its view and wishes to The Aid to Science Commission."

If, eventually, only the smaller scheme be adopted, it is thought the cost of the whole building and the purchase of the site could be compassed by an outlay which would offer no pecuniary impediment. In the absence, however, of working plans any stated sum can only be regarded as roughly approximate. The site itself may prove a business not so easily dealt with. Position is a matter of such precious importance to the utility of the undertaking that it is not likely to be undervalued-success or failure very much hangs upon the local habitation.

The proceedings of the committee seem to have been thus far, prompt and business-like. We have no doubt, therefore, that their efforts to economise the resources, and thereby augment the utility of the scientific societies of the metropolis, will speedily bear good fruit.

\section{THE BERLIN WORKING MEN'S CLUB}

FOR some years past there has been carried on at Berlin a Working Men's Club (for so it seems best to translate Der Berliner Handwerker Verein), established, we are told in its Reports, by working men and friends of labour, in order to promote general culture, sound technical knowledge, and good manners, among its members. This it attempts to do by means of popular lectures, classes for serious instruction, gymnastics, a library and reading-room well stocked with books and journals, concerts and social gatherings, or pleasure parties in which the wives and children of members take part. In many respects it resembles our own Mechanics' Institutes and Working Men's Clubs; but there are several features deserving special attention.

Not the least noteworthy point about it is its success. The average number of members at any one time is about 4,000, of whom nine-tenths at least are bonat fide working men; but owing to the migratory habits of the German artizans, no less than 10,000 names are placed on their books every year. Well worthy of attention is the essentially democratic nature of the constitution and management. It is founded on the principle of self-help; 